\title{
Tracking Changing Evidences of Water in Wetland Using the Satellite Long-Term Observations from 1984 to 2017
}

\author{
Zhijie Zhang ${ }^{1,2}{ }^{\oplus}$, Liping Lei ${ }^{1, *}$, Zhonghua He ${ }^{1,2,3}$, Yali Su ${ }^{1}$, Liwei Li ${ }^{1}$, Xiaofan Wang ${ }^{4}$ \\ and Xudong Guo ${ }^{4}$ \\ 1 Key Laboratory of Digital Earth Science, Aerospace Information Research Institute, \\ Chinese Academy of Sciences, Beijing 100000, China; zhangzj2018@radi.ac.cn (Z.Z.); hezhh@radi.ac.cn (Z.H.); \\ syl1501235615@163.com (Y.S.); lilw@radi.ac.cn (L.L.) \\ 2 College of Resources and Environment, University of Chinese Academy of Sciences, Beijing 100000, China \\ Zhejiang Climate Center, Hangzhou 310000, China \\ 4 Key Laboratory of Land Use, Ministry of Natural Resources, China Land Surveying and Planning Institute, \\ Beijing 100000, China; wangxf.10s@igsnrr.ac.cn (X.W.); sam9560@vip.sina.com (X.G.) \\ * Correspondence: leilp@aircas.ac.cn; Tel.: +86-139-1173-9509
}

Received: 18 April 2020; Accepted: 1 June 2020; Published: 4 June 2020

\begin{abstract}
Wetlands have been degrading and reducing under the influences of human activity and climate change. Landsat long-term observations can help us better track the changing evidences of wetland habitats that would be valuable for guiding the restoration and conservation of wetland. In this study, we demonstrated the results of tracking the changing evidence of wetland habitats using Landsat observations from 1984 to 2017 through the case study of Baiyangdian wetland in China. We extracted the open water and classified the wetland habitats using collected 190 scenes from Landsat observations. As a result, we found that the yearly variations of wetland present phasic changes in three phases: 1988-1998, 1999-2011 and 2013-2017. The landscape of wetland habitats presented during 1989-1999 mostly show us the natural spatial pattern with less human disturbance traces compared to that during 2013-2017. The water environment, moreover, changed for the better after the 2010s, which indicated the encouraging effects of the environmental restoration project implemented from the year 2010. The current landscapes of wetland habitats, however, present lots of linear belts that are blocking the water cycles and ecological channels of aquatic plants and animals in the wetland. The areas in the northwestern wing and around the northeastern edge of the wetland are changing to be drier due to cropping activities and are at risk of wetland loss. These historical changing evidences could be a guideline for planning and designing restoration for the wetland.
\end{abstract}

Keywords: wetland; human disturbance; changing detection; satellite observation

\section{Introduction}

Wetland, a rare and valuable natural resource, is one of the most important ecosystems on Earth. It has the capability of providing various ecosystem functions, including adjusting climate, providing habitats for aquatic plants and animals, filtering polluted water, alleviating floods and leisure parks, etc., [1]. The wetlands, especially located in a heavily populated region, are suffering the damages of habitats, losses of biodiversity within the wetland and being converted to other uses induced by human activity, as wetland unique habitats are underappreciated [1]. However, there are good signs that many projects are being initiated and implemented to stop the global loss and damage of wetland, and restore and conserve those that remain. In the restoration project for those wetlands damages caused by human disturbance and climate changes, it is substantially better to know what the natural 
wetland habitats and landscapes that we want to restore should be like, which can be found from reviewing the historical changes of wetland habitats in the long-term.

The satellite long-term observations can help us better to know the changes in wetlands and review the past wetland habitats and landscapes that may be undamaged by human disturbances $[2,3]$. Landsat observations, from Multispectral Scanner (MSS), Thematic Mapper (TM), Enhanced Thematic Mapper Plus (ETM+) and Operational Land Imager (OLI) sensors, have accumulated long time data of 45 years. These data have been applied in an extensive investigation of wetland as there are reliable and mature data processing methods available such as extracting water, classification, change detection, etc., [4-8]. Some research assessed the water extent, loss, gain, and type conversions of wetland using Landsat observing data during the years of 1979-2015 [9-11]. The mapping of wetland yearly and type conversions of wetland were mostly implemented using the yearly season observing data of Landsat during 1978-2008 [8,10,12-16]. Zhu et al. classified the land cover of wetland, including water, floating vegetation, emergent vegetation, paddy field, cropping fields and built-up, in Baiyangdian wetland every five years using Landsat data from 1975 to 2018 and explored their type conversion by the classifying results [16]. The research above mostly focused on demonstrating the mapping, classification, changes of loss and types conversion of wetland, lacking investigations of subtle changes of wetland habitats and reviewing the inherent habitats of wetland. The diverse habitats of wetland are varied seasonally and yearly under the influence of climate and human activity, and are the interaction e.g., the water extent and aquatic vegetation would maintain an equilibrium ratio within the wetland as the water could affect and be affected with the growth of aquatic vegetation in lake wetland like Baiyangdian wetland.

This paper selects a typical wetland strongly disturbed by human activities, the Baiyangdian wetland, as the study area, aims to review the changes of wetland habitats and find the inherent habitats using the long-term satellite observations. Baiyangdian, a scarcity wetland resource in North China, plays an important role in adjusting regional climate, filtering polluted water, providing habitats for aquatic animals and plants, human leisure and so on. Because of its favorable environmental conditions in addition to facilitating access to Beijing, a new economic development area nearby the wetland, called Xiongan New Area, has been planned and implemented to relieve the stress of business and population increases in Beijing. The Baiyangdian wetland, however, has experienced strong impacts of disturbances and damages from human activities, such as water transportation, cropping, building houses, fish farming, leisure parks, etc. The restoration of the Baiyangdian wetland has been one of the most important issues in developing the Xiongan New Area. Many types of research for Baiyangdian wetland focused on its general change and driving factors assessment [16-18]. The changing analysis over more than 30 years only used the years' data by sampling the Landsat observing time in 3-5 years interval rather than using the continuous time-series data each year $[17,18]$. These investigations did not track changing evidences elaborately to find more valuable information for wetland restoration and protection although Landsat observations have provided us over 200 scenes available in a long time-series from 1984 in this area.

In this paper, we presented the results tracking the changing evidences of water frequency and wetland habitats using a long-term Landsat observation during 34 years from 1984 to 2017 and probe the natural habitats and landscape of wetland in the study area, that is Baiyangdian wetland, a lake wetland. This study presents a case study of applying long-term satellite observations to provide assistant strategic information for the restoration of wetland environments.

\section{Data and Methods}

\subsection{Study Area and Data}

\subsubsection{Study Area}

The study area, the extent of $2145 \mathrm{~km}^{2}$ covering Baiyangdian wetland and land around the wetland, is located in the county of Anxin in Hebei province, China (Figure 1). Baiyangdian wetland 
is the largest natural lake wetland that remains in the North China Plain. This wetland, surrounded by farmlands and residents, is strongly disturbed by human activities such as water transportation, cropping, building houses, fish farming, and leisure parks, etc. Baiyangdian wetlands mainly consist of the water body, aquatic vegetation, few crop fields, and tiny spots of houses (Figure 1b). The aquatic vegetation, including floating and emergent plants, seasonally grows over the water surface from June to September, while the water body becomes visible during the non-growing season of this aquatic vegetation [19]. The water body that the satellite observes is the water surface uncovered by aquatic vegetation, which is called open water hereafter. Water is the most important ecological factor in Baiyangdian wetland, which is recharged by the rivers from precipitation and artificial recharge water [20]. The water depth changes from dozens of centimeters to five meters [21]. The amount of water flowing into wetland from the rivers has been declining due to the large increase in human water over-usage, including agricultural irrigation, industrial and household water consumption. To maintain the aquatic environment of wetland, the works of artificial water have been implementing each year since the 1990s through drawing the water from the river and current South-to-North Water Transfer Project to wetland [22,23].

(a) $115^{\circ} 37.37^{\prime} \mathrm{E}, 39^{\circ} 1.71^{\prime} \mathrm{N}$

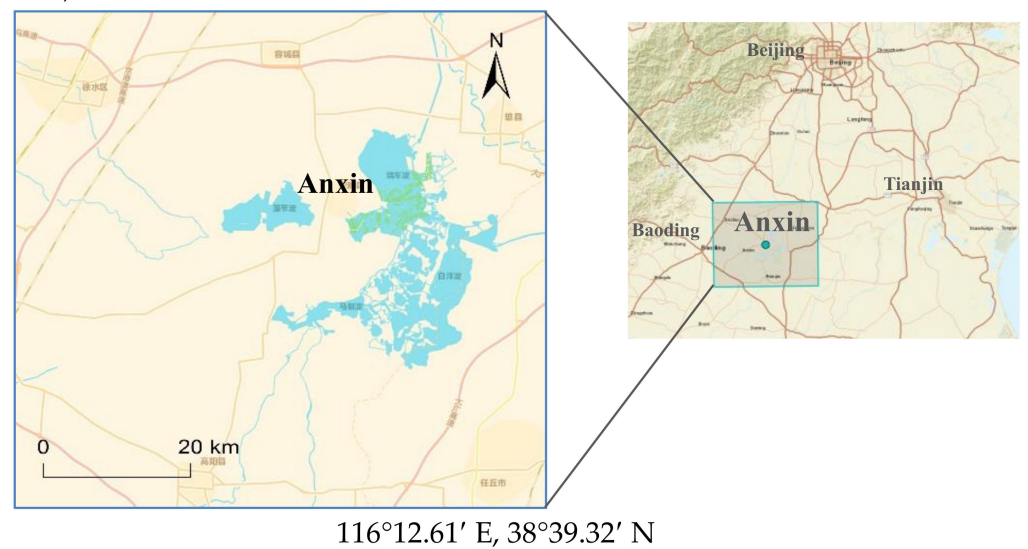

(b)

$116^{\circ} 12.61^{\prime} \mathrm{E}, 38^{\circ} 39.32^{\prime} \mathrm{N}$
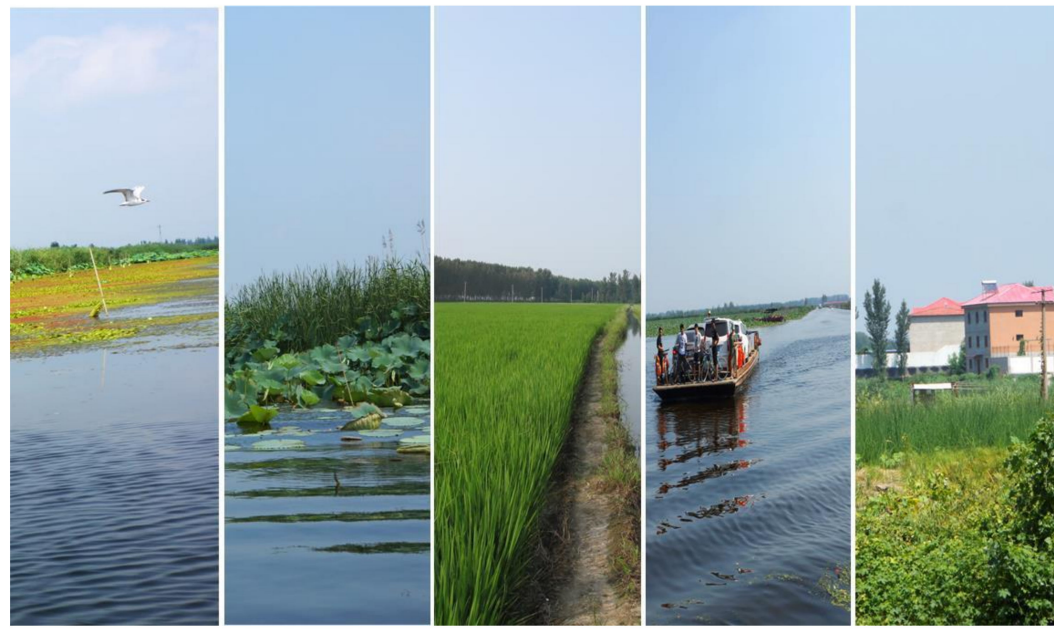

Figure 1. Overview of the study area where (a) is the location of Baiyangdian wetland and (b) show typical natural and manmade landscapes in the wetland, that is floating vegetation and open water in the first column, emergent vegetation of reeds, cattails and lotus, and open water in the second column, paddy and trees in the third column, water traffic in the fourth column, and residential houses and cropping in the last column from the left to right photos, respectively. 


\subsubsection{Satellite Data}

We collected available L1T products data of Landsat time-series from 1984 to 2017 released by the United States Geological Survey (USGS) over the study area (WRS-2 path/row 123/33) (url: https://espa.cr.usgs.gov/). The data are at $30 \mathrm{~m}$ spatial resolution from observations of TM, ETM+ and OLI sensors onboard Landsat 4, 5, 7 and 8, respectively. The 190 fully cloud-free time-series scenes during 34 years from 1984 to 2017 were collected in the study area. Generally, the four seasons of each year have available data (Figure 2) excluding the 5 years in 1985, 1986, 2007, 2010, 2012, which have less than two scenes available due to the influence of cloudy coverage and data quality. The digital number of Landsat L1T data was converted to the reflectance at the top of the atmosphere using calibrating coefficients provided in the product metadata (MTL) file and the introduced algorithms by the Landsat missions (url: https://landsat.usgs.gov/calibration-parameter-files-search).

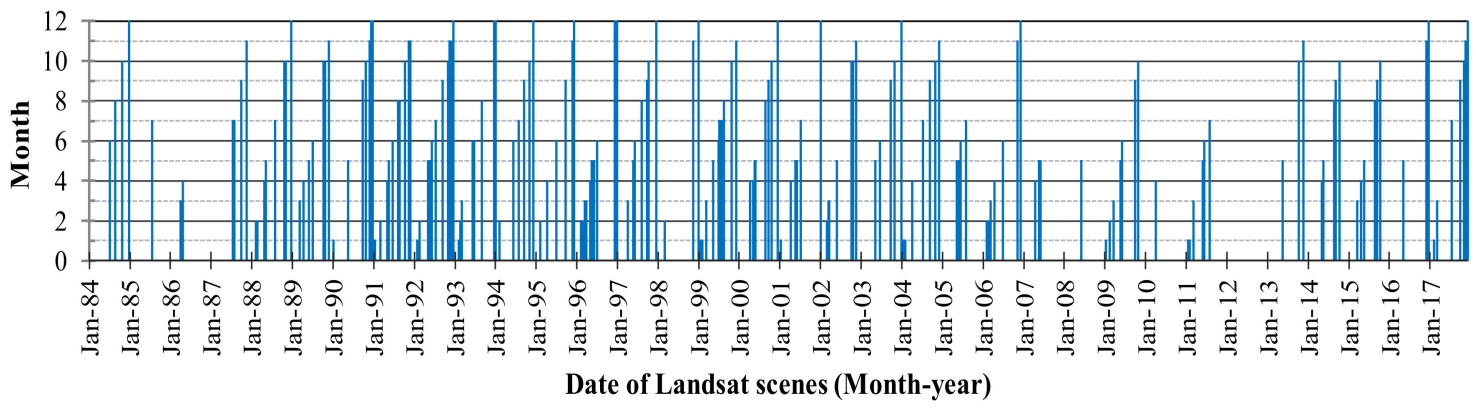

Figure 2. Seasonal distribution of collected Landsat scenes from 1984 to 2017.

Additionally, we collected high spatial resolution data on 2 Mar 2017 from Geofen satellite observations (GF-2) at $2 \mathrm{~m}$ resolution, which is pan-sharpened by $4 \mathrm{~m}$ multi-spectral and $1 \mathrm{~m}$ panchromatic data released by the China Resources Satellite Applications Center (url: http://cresda. com/CN/). These data are used to certify the results derived from Landsat. We also collected precipitation observed from 1984 in Anxin town and the artificial recharge water column reported by the reference [23].

\subsection{Method}

The approach of processing and analysis is shown in Figure 3. We utilized ENVI tools to implement the clustering analysis, computing, and the process of certifying and improving the results by the interaction between visual interpretation and computer processing. We applied the effective and reliable threshold approach of detecting water and clustering analysis used currently. The processing of extracting water is finished by MATLAB program built by authors. 


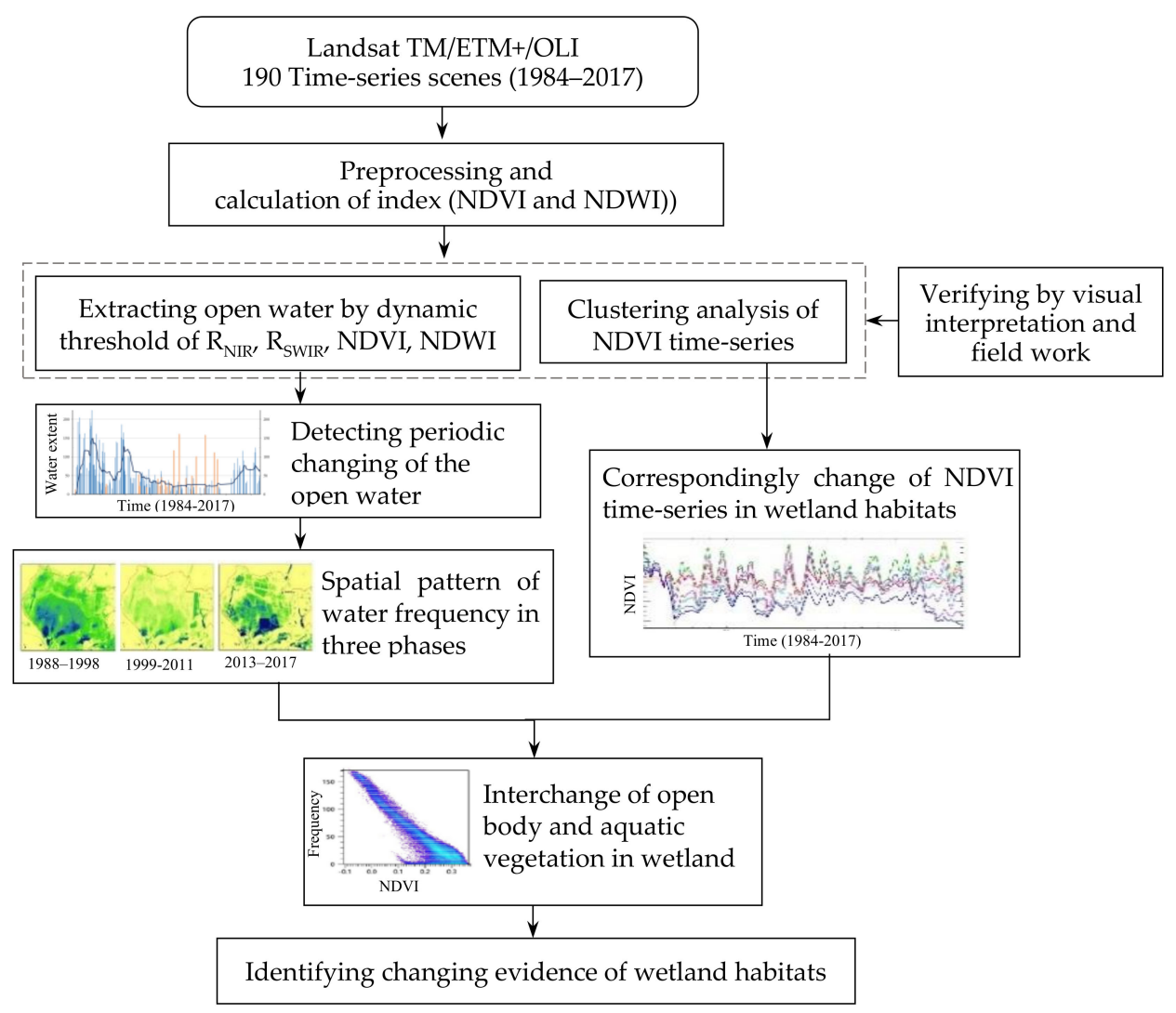

Figure 3. Flow chat of tracking changing evidences of water in wetland using the satellite observing data.

\subsubsection{Detection of Open Water in the Wetland}

Water in Baiyangdian, as the nutrient source of aquatic plants, is an essential factor of wetland habitats. The water can be well identified by the threshold method using the reflectance in near-infrared $\left(\mathrm{R}_{\mathrm{NIR}}\right)$, shortwave infrared $\left(\mathrm{R}_{\mathrm{SWIR}}\right)$, normalized difference vegetation index (NDVI), and normalized difference water index (NDWI) [4,6-8]. We extracted the open water in each scene of the Landsat data using the dynamic threshold approach in $\mathrm{R}_{\mathrm{NIR}}, \mathrm{R}_{\mathrm{SWIR}}$, NDVI, and NDWI, based on computer identification and manual interpretation to ensure consistency and accuracy of the results in the time-series.

Regarding changeable thresholds and certification of results, we adopted 5 scenes as a processing unit to fix the thresholds of $R_{\text {NIR }} R_{S W I R}$, NDVI, and NDWI, and certified the results by visual interpretation. Firstly, selecting the initial interesting region (ROI), which are the open water for all scenes in the study area as much and unchanged as possible. Then, as described below, the extracting pixels of open water for 5 scenes involve the following three steps: (i) filtering the non-water pixel in ROI to output filtered pixels (FPn, $n=0$ ) if it is larger than 0.2 in $R_{N I R}$ as the water reflectance is lower than non-water in $R_{\text {NIR }}$; (ii) fixing the thresholds of $R_{\text {NIR }} R_{\text {SWIR }}$, NDVI, and NDWI by loop of filtering non-waters in $\operatorname{FPn}(n=1, \ldots, \mathrm{m})$ if the value of pixel is $\mathrm{R}_{\mathrm{NIR}}>\mu_{\mathrm{NIR}}+2^{*} \sigma_{\mathrm{NIR}}, \mathrm{R}_{\mathrm{SWIR}}>\mu_{\mathrm{SWIR}}+2^{*} \sigma_{\mathrm{SWIR}}$, NDVI $>\mu_{\text {NDVI }}+2^{*} \sigma_{\text {NDVI }}$, NDWI $<\mu_{\text {NDWI }}-2^{*} \sigma_{\text {NDWI }}$ until without non-water pixel in FPn, where $\mu$

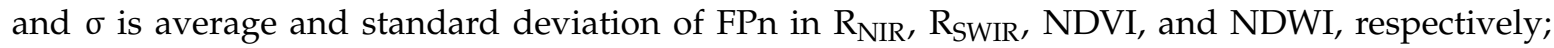
(iii) extracting the water pixels using $R_{\text {NIR }} R_{S W I R}$, NDVI, and NDWI data of each scene by the thresholds fixed last step. The binary image, the value of water and non-water is 1 and 0 , respectively, is generated. Through the processing above of each 5 scenes unit repeatedly, we obtained 190 time-series data of open water during 1984-2017 using collected Landsat data.

We certified the results of extracted open water for the initial ROI in selected 36 scenes by visual interpretation of the color compositing image of Landsat. Considering the seasonal variation of open water, selecting 3 scenes each season including spring, summer, autumn, and winter, respectively, 
in 10-14 years interval during 1984-2017. The results showed the accuracy of extracted open water is generally up to $90 \%$ in ROIs of 36 scenes by visual interpretation.

\subsubsection{Clustering Analysis of Wetland Habitats}

The time-series NDVI data can demonstrate the variety of wetland habitat for each pixel, where aquatic vegetation presents the highest NDVI and open water shows the lowest NDVI. We classified the time varying pattern of NDVI to assess the wetland habitats by the iterative self-organizing data analysis technique algorithm (ISODATA) of the NDVI time-series data. The classified area focused on the buffered $1 \mathrm{~km}$ wetland range in 1989 by masking the peripheral area. The number of initial classes is set to 16 classes in ISODATA. The wetland range in 1989, which tends to be the maximum during 1984-2017, was delineated by visually interpreting the color composited image of Landsat data in 1989.

We attributed the features of wetland habitats to 12 classes from ISODATA, classifying results based on the time varying characteristics of each average NDVI clustered class and the visual interpretation of color images composited by Landsat and GF-2 data. The 12 classes generally are concluded in two categories that are the classes unchanged and the classes disturbed by human activities over the years. The classes unchanged, referred to as natural classes, also include 4 classes that are open water, open water mixed with aquatic vegetation, floating vegetation, and emergent vegetation. The classes disturbed mostly indicate the human activities disturbing during 34 years, including fishpond, mixed-grass that is degrading aquatic vegetation, paddy fields that were cultivating the rice or lotus over some time, built-up unchanged and increased, trees and loss by cropping.

The accuracy of classes was checked by the field investigation and visual interpretation of high spatial resolution true-color GF-2 image. The certification of classes, in 122 ground sites investigated in June 2017, yielded the overall accuracy of 93\%. The result of classification is generally reasonable based on the visual interpretation of the GF-2 image.

\section{Results}

\subsection{Periodic Changing of Open Water Extent in the Wetland}

We calculated the open water extent in the whole wetland range of 2017 for each scene by open water detected from Landsat scenes. The border of wetland range is obtained from the visual interpretation of Landsat images in 2017. Figure 4 presents the temporal variation of open water extent $\left(\mathrm{km}^{2}\right)$ combined with water volume $\left(\times 100 \mathrm{~m}^{3}\right)$ of the artificial water recharge, yearly variation of open water extent in November and December, and monthly precipitation from 1984 to 2017. The open water extents in November and December tend to be a peak in a year, as the extent of aquatic vegetation covering the water body is the least, with aquatic plants withered in this period.

The open water extent was almost zero from 1984 to 1988 although the precipitation, one of the main sources of recharge water to Baiyangdian wetland, did not show the lowest during this period (Figure 4). This result likely related with large decreases of water recharge from upstream watersheds due to massive drainage for agriculture and urban development, and extreme reservoir constructions with quick economic growth in China [22,23]. The open water extent sharply increased and recovered after 1988 because of precipitation greatly increasing. The yearly variation of open water extent significantly shows cyclic fluctuations in three phases from both multi-temporal variation and yearly peak variation from 1988 to 2017 (Figure 4): the first phase is large extent during 11 years from 1988 to 1998; the second is less extent during 13 years from 1999 to 2011 and the third is an increasing trend during lastly 5 years from 2013 to 2017 . The open water extents averagely accounted for $35 \%, 12 \%$ and $25 \%$ of wetland range in these three phases, respectively. The least water extent in the second phase is most likely associated with fewer precipitations and decreases in water recharge from upstream watersheds caused by human activities especially when Chinese economic growths were the fastest. Owing to the artificial water recharges many times during this second phase (Figure 4), the water 
in wetland did not dry up, just like the period of 1984-1988 [23]. The artificial water recharges are being implemented still by local government in spring each year to maintain the fundamental water need of the wetland habitat according to the reports from the news of governmental work and our field investigation.

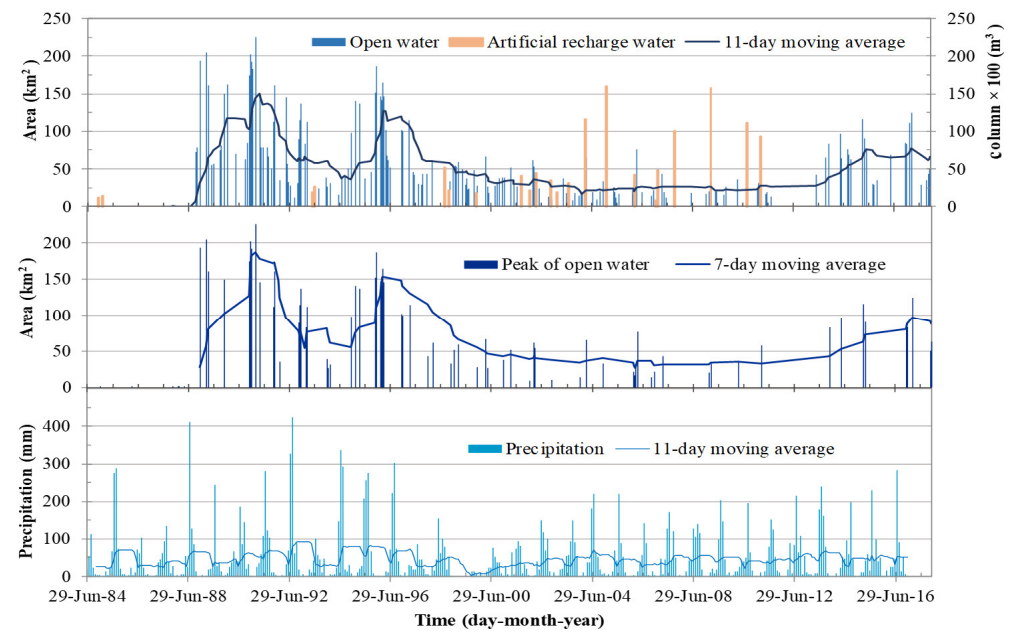

Figure 4. Time variation of open water extents within the wetland range in 2017 for 190 scenes and precipitation from 1984 to 2017. The upper graph is a multi-temporal variation of open water extent $\left(\mathrm{km}^{2}\right)$ overlaid over the artificial water recharge volume $\left(100 \mathrm{~m}^{3}\right.$ unit), the middle is the peak of open water extent $\left(\mathrm{km}^{2}\right)$ each year in November and December, and the bottom is the monthly precipitation in the same year.

Figure 5 shows these periodic changes in the wetland visually by the examples of Landsat color composite images all observed in October, which demonstrate dried up wetland in 1984, a large water extent in 1989 in the first phase, less water extent in 2009 in the second phase and current wetland in 2017 in the third phase. The area of wetland in $2017\left(258 \mathrm{~km}^{2}\right)$, reduced $42 \mathrm{~km}^{2}$ compared to the maximum area $\left(300 \mathrm{~km}^{2}\right)$ that appeared in 1989 during 1984-2017. 

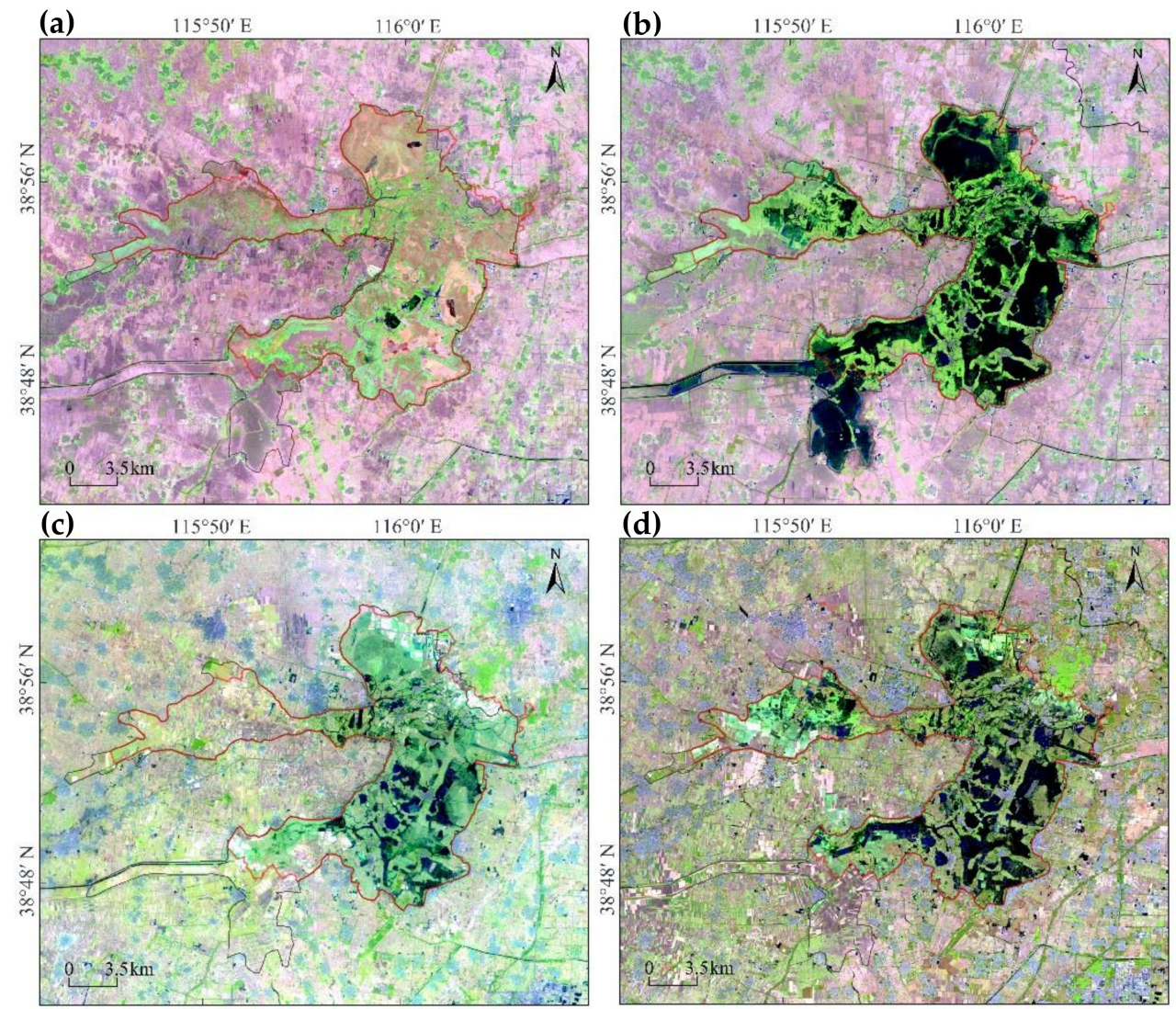

Figure 5. Landsat images of wetland habitat in (a) dried up wetland on 19 October 1984; (b) a large water extent on 17 October 1989 in the first phase; (c) less water extent on 24 October 2009 in the second phase and (d) current wetland on 30 October 2017 in the third phase, which are the color composition of RGB, (a-c) are from combination of bands 5,4,3 of TM data and (d) is bands 6,5,4 of OLI data, respectively. The red polyline and black polyline are the wetland range of 2017 and 1989, delineated by the visual interpretation of Landsat image, respectively.

\subsection{Interchanges of Water Body and Aquatic Vegetation in Wetland}

The wetland habitat of Baiyangdian, as a lake-type wetland, is primarily composed of the water body and aquatic vegetation, where the water body is the nutrient source of aquatic plants [20]. We calculated the time cumulative frequency of open water for each pixel in 190 scenes of Landsat time-series data from 1984 to 2017 (Figure 6). Figure 6 presented the spatial pattern of the hydrological conditions of wetland habitats. The less the frequency is, the drier the wetland tends to be in Figure 6 . The maximum frequency of open water is 179 rather than 190 using all Landsat temporal scenes as there is open water extracted within the wetland in 11-temporal scenes due to the wetland drying up in during 1984 to 1988 (Figure 5a).

Figure 7 presents the classes of wetland habitat derived from the clustering of NDVI time-series variation from 1984 to 2019 and temporal variations of NDVI for the typical classes averaged across the wetland area. Figure 7a, compared with Figure 5, demonstrates that the classes unchanged, including open water and aquatic vegetations, generally show greater water frequency than those classes disturbed such as paddy cultivation, built-up, etc. This result indicates human activities had induced the degradation of water conditions. 


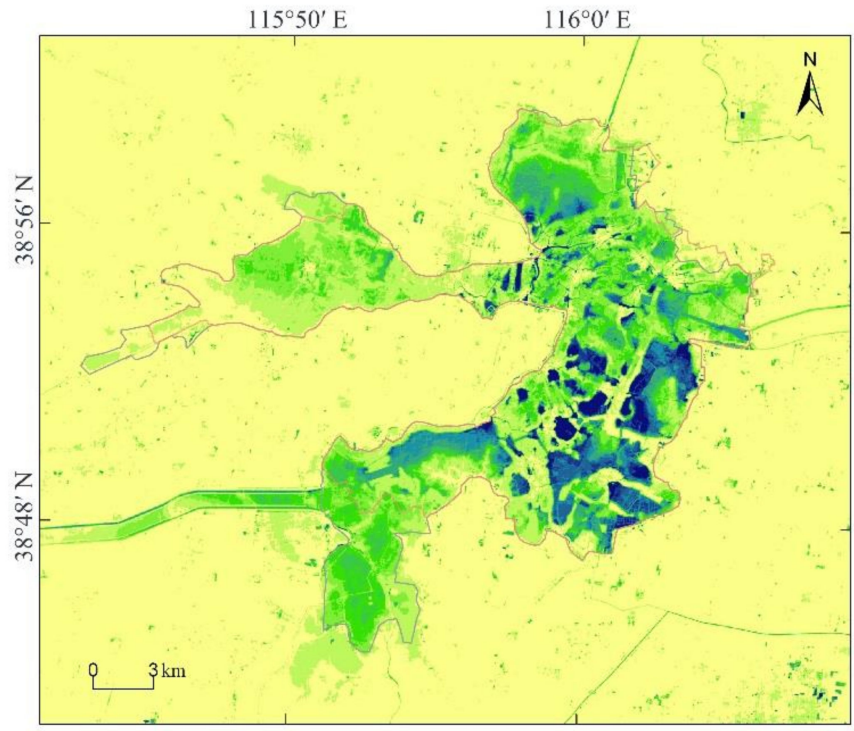

Frequency

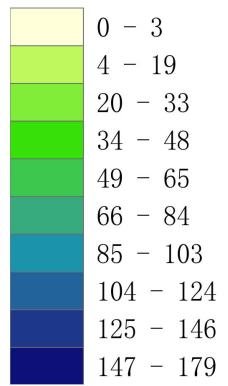

〜 Area of wetland in 2017

Area of wetland in 1988

Figure 6. The time cumulative frequency of open water during 34 years from 1984 to 2017 derived from the cumulation of open water extracted in 190 temporal scenes, where the red polyline and black polyline is the area of wetland in 1989 and 2017, respectively.

It is known that NDVI of water is much smaller than that of aquatic vegetation, and the smaller NDVI, the cleaner the water [2,9]. The NDVI dispersion across all of the classes in time, that is the difference of NDVI between water and aquatic vegetation, reveals the diversity of wetland habitats. Figure $7 \mathrm{~b}$ shows that the general variation of NDVI dispersion also demonstrated similar cyclic fluctuations in three phases from 1988 to 2017 to the variations of open water extent (Figure 5) described above. The NDVI variation in the third phase from 2013 to 2017 is greater than the first phase and second phase, and NDVI of open water significantly changed to be the lowest in recent years. This result likely indicated that the water is changing to be cleaner, since water pollution is being controlled by the government implementing environmental improvement projects starting from the 2010s.

The wetland in the first phase from 1988 to 1998 presented the maximum water extent and regular NDVI variations (Figures 4 and $7 b$ ), which implies fewer disturbances of human activities. Thereby we classified the habitats of wetland using NDVI time-series data in this period (Figure 8) by the same method as the classification shown in Figure 6.

Comparing Figure $7 \mathrm{a}$ to Figure 8, the current wetland habitats have been largely changed. The area of natural habitats such as open water, floating vegetation, and emergent vegetation accounted for $94 \%$ of the whole wetland range in 1988 in the first phase of 1988-1998, whereas these classes were reduced to $61 \%$ of the whole wetland range in 2017 (see the bold texts in Table 1). The area of emergent vegetation reduced from $52 \%$ to $33 \%$ from 1989 to 2017. The area of the classes indicating human activities such as paddy fields, mixed grass and built-up increased from 14\% to 39\% from 1989 to 2017. They generally distribute in the northwestern wing of wetland and around the northeastern edge of wetland (Figure 7a), where the frequency of open water showed the lowest also (Figure 6), which implies they are at risk of wetland loss. 
Table 1. Statistics for the classes in the wetland range of 2017.

\begin{tabular}{|c|c|c|c|c|}
\hline Class & $\begin{array}{c}\text { Area }\left(\mathrm{km}^{2}\right) \\
\text { (Percent in } \\
1989 \text { Wetland) }\end{array}$ & $\begin{array}{c}\text { Area }\left(\mathrm{km}^{2}\right) \\
\text { (Percent in } \\
2017 \text { Wetland) }\end{array}$ & $\begin{array}{l}\text { NDVI in } \\
\text { Growing Season } \\
\text { (10 July 2017) }\end{array}$ & $\begin{array}{l}\text { Frequency of } \\
\text { Open Water for } \\
2017 \text { Classes }\end{array}$ \\
\hline Open water & $37.04(12 \%)$ & $20.88(8 \%)$ & -0.19 & 137 \\
\hline $\begin{array}{l}\text { Open water mixed with } \\
\text { aquatic vegetation }\end{array}$ & $30.75(31 \%)$ & $24.98(10 \%)$ & 0.29 & 94 \\
\hline Floating vegetation & $28.14(9 \%)$ & $26.46(10 \%)$ & 0.55 & 54 \\
\hline Emergent vegetation & $156.40(52 \%)$ & $84.82(33 \%)$ & 0.71 & 30 \\
\hline Fishpond & None & $11.58(5 \%)$ & -0.03 & 63 \\
\hline Mixed grass & $3.02(1 \%)$ & $27.98(11 \%)$ & 0.64 & 15 \\
\hline Paddy field & $17.38(6 \%)$ & $34.10(13 \%)$ & 0.66 & 23 \\
\hline Trees & $14.22(5 \%)$ & $10.40(4 \%)$ & 0.59 & 4 \\
\hline Built-up of resident & $5.54(2 \%)$ & $3.26(1 \%)$ & 0.18 & 8 \\
\hline Built-up increased & None & $4.50(2 \%)$ & 0.25 & 21 \\
\hline Loss in cropping & None & $7.64(3 \%)$ & 0.59 & 39 \\
\hline Farmland & $7.53(3 \%)$ & $1.83(1 \%)$ & 0.54 & 3 \\
\hline Total area $\left(\mathrm{km}^{2}\right)$ & 300.02 & 258.43 & & \\
\hline
\end{tabular}

(a)

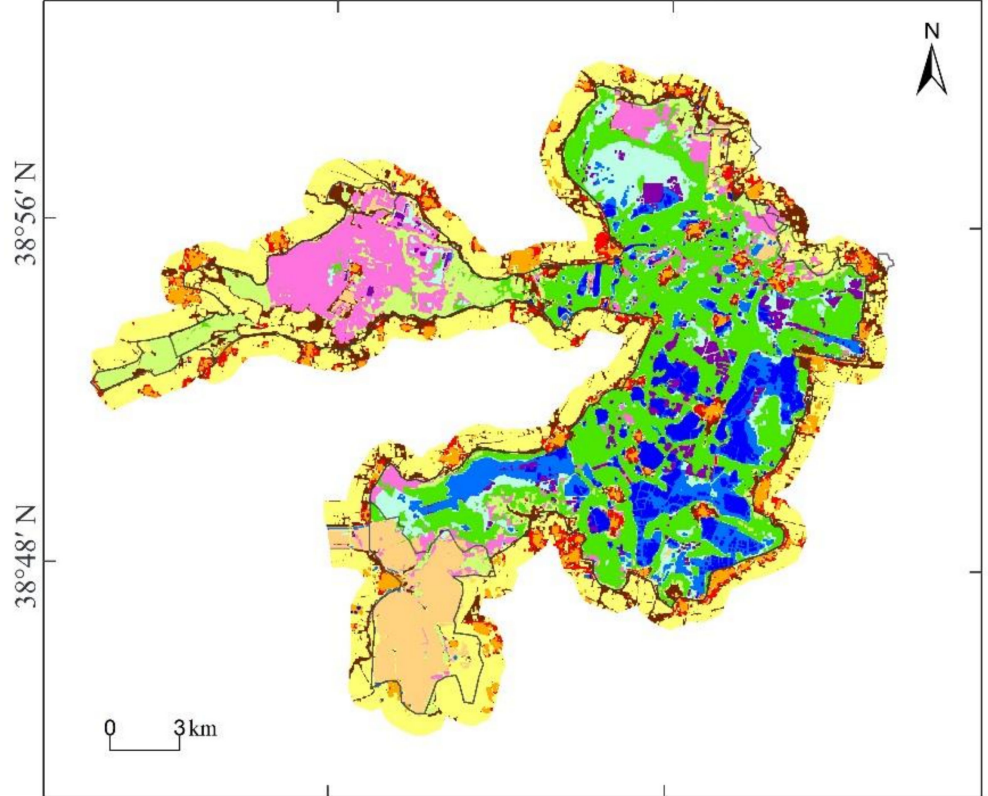

Class unchanged

- Open water

- Open water mixed with aquatic vegetation

Floating vegetation

Emergent vegetation

Class disturbed

- Fishpond

- Mixed grass

Paddy field

- Trees

Built-up of resident

- Built-up increased

- Loss in cropping

Farmland

$\sim$ Border of wetland in 2017

$\sim$ Border of wetland in 1988

(b)

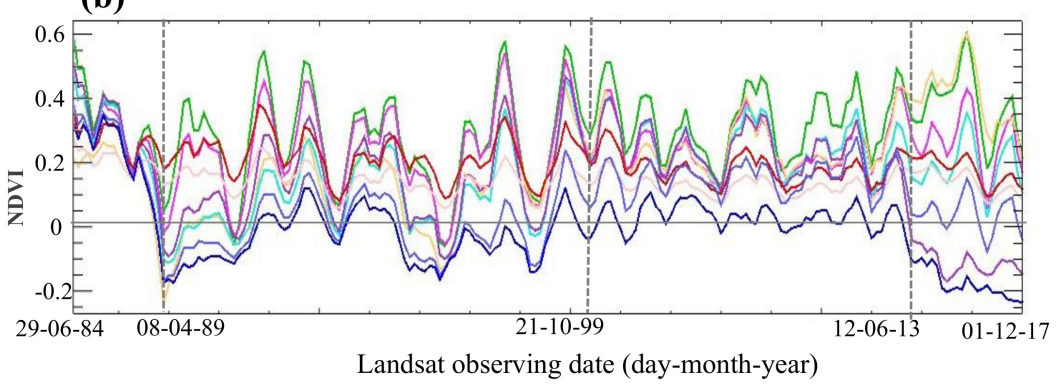

- Open water

- Open water mixed with aquatic vegetation

- Floating vegetation

- Emergent vegetation

- Fishpond

- Paddy field

Built-up unchanged

- Built-up increased

Landsat observing date (day-month-year)

Figure 7. (a) The classes of wetland habitats obtained by clustering NDVI time variations from 1984 to 2017 and (b) time smoothed variations of averaged NDVI for typical classes across the wetland range of 2017. 


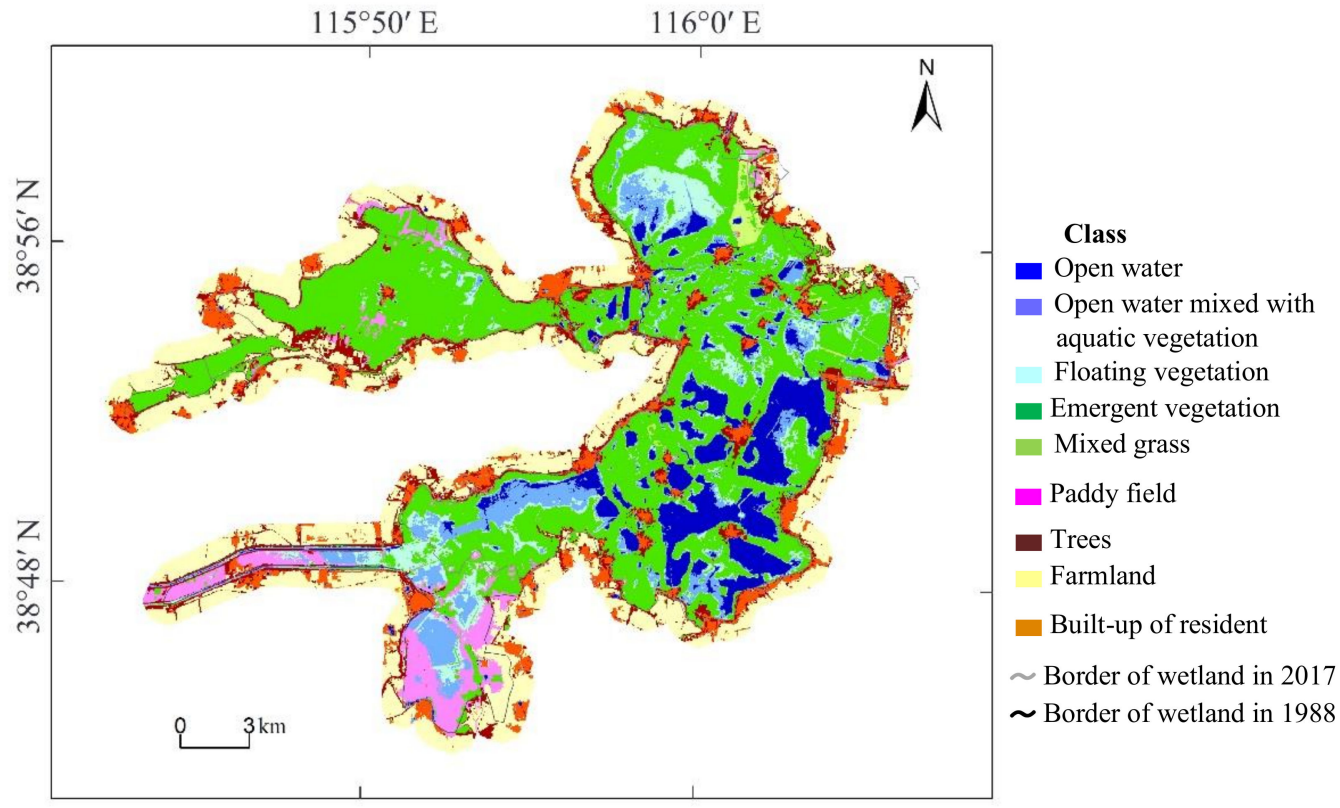

Figure 8. The classes of wetland habitats in the first phase derived from the clustering of NDVI time-series data from 1988 to 1999.

\section{Discussion}

The standard deviation of time-series NDVI is significantly much greater than that of land (Figure 9a), which indicates the sharply seasonal alternation of aquatic vegetation and water in the wetland. The histogram of time averaged NDVI and water frequency, as shown in Figure $9 \mathrm{~b}$, demonstrates that alternation of aquatic vegetation and water mostly occurs over emergent vegetation with $0.3 \pm 0.3$ of NDVI and $6 \%-20 \%$ of total water frequency.
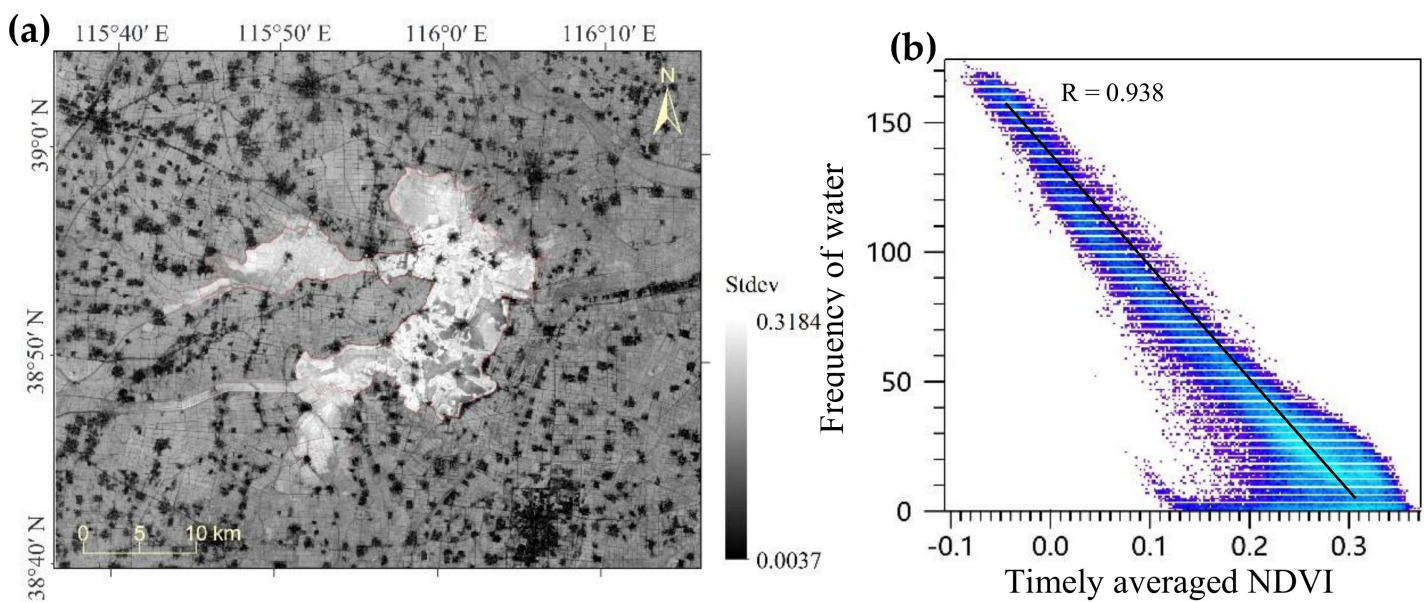

Figure 9. Interacting changes of aquatic vegetations and water in wetland, (a) The standard deviation (Stdev) of NDVI time-series data from 1984 to 2017; (b) Histogram of time averaged NDVI and the cumulative frequency of open water from 1984 to 2017 for the pixels within the wetland range of 2017, where the gradient colors from blue to cyan mean the number of pixels within the wetland from the least to the most.

To probe the changes of wetland in the three phases obtained above, we calculated the density of open water each pixel in the three phases respectively, by cumulating the number of extracted open water divided by the whole number of used temporal during a period that is 75 temporal in the first phase of 1988-1998, 72 temporal in the second phase of 1999-2011, and 24 temporal in the third phase 
of 2013-2017. Figure 10 presents the water density images in the three phases across the study area and two local areas, which are mostly leisure parks and fishponds. Table 2 shows the statistical results of open water extent, density, and NDVI across the whole wetland of 2017 for the three phases.
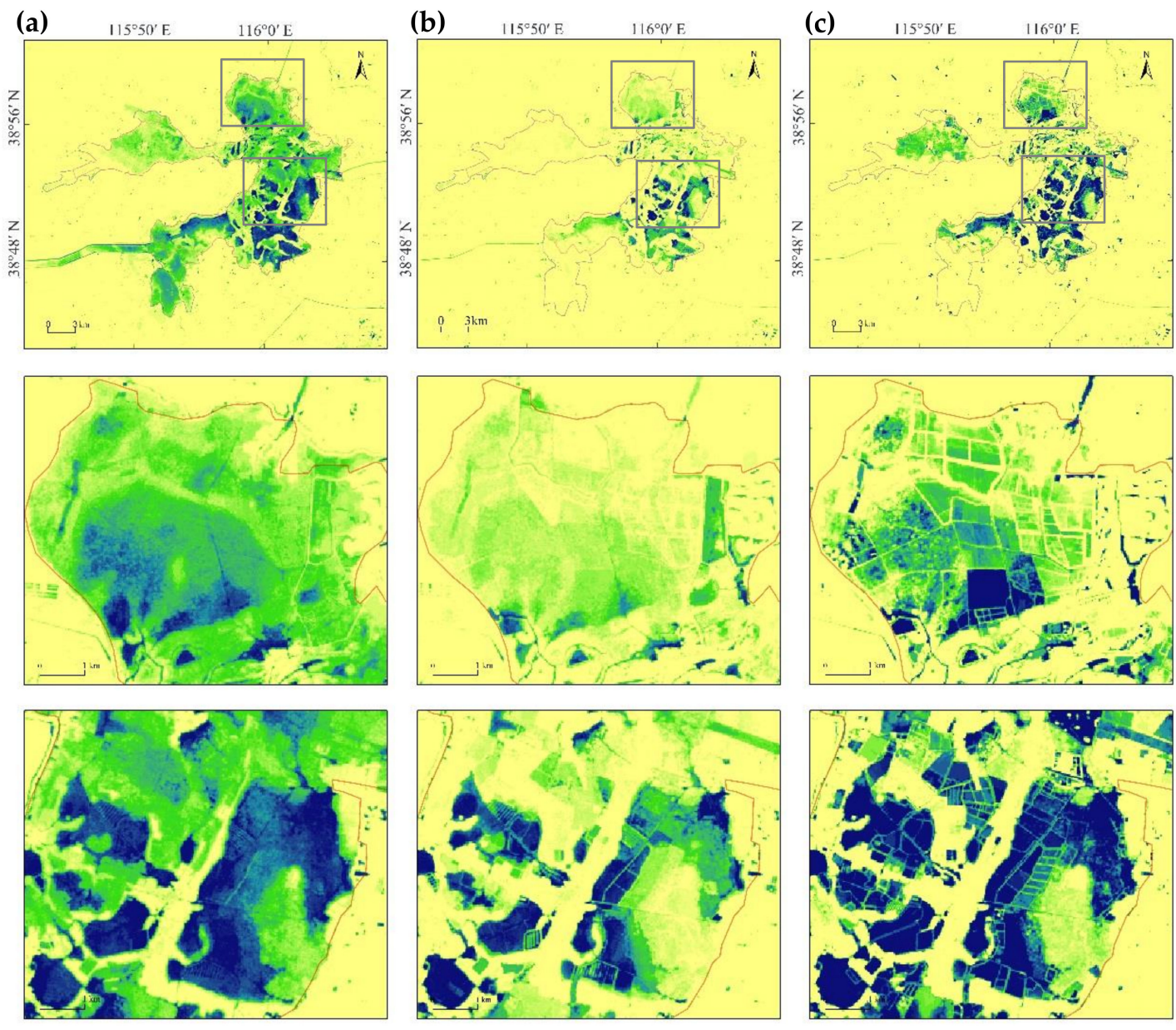

Density (\%)

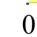

25

50

75

100

Figure 10. The density images of open water in the three phases as for (a) left column is the first phase of 1988-1998, (b) middle column is the second phase of 1999-2011, (c) right column is the third phase of 2013-2017, which are derived from extracted open water data using 190 Landsat scenes.

Table 2. The averaged open water extents, and density of open water and NDVI across the whole of wetland in 2017 and annual mean precipitation in the three phases.

\begin{tabular}{cccccc}
\hline \multirow{2}{*}{$\begin{array}{c}\text { Time of } 3 \\
\text { Phases }\end{array}$} & \multicolumn{2}{c}{ Open Water } & NDVI & $\begin{array}{c}\text { Annual Mean } \\
\text { Precipitation (mm) }\end{array}$ \\
\cline { 2 - 5 } & Extent $\mathbf{( k m}^{\mathbf{2}}$ ) & Density (\%) & Mean & Stdev & \\
\hline $\begin{array}{c}\text { 1st phase } \\
\text { 1988-1998 }\end{array}$ & 83 & 26 & 0.168 & 0.145 & 678 \\
2nd phase & & & & & \\
1999-2011 & 29 & 13 & 0.238 & 0.128 & 477 \\
3rd phase & 68 & 30 & 0.218 & 0.225 & 613 \\
2013-2017 & & & & & \\
\hline
\end{tabular}

We can see from Figure 10 that Baiyangdian wetland, mosaicking in the agriculture region, is severely affected by human disturbance. The current landscape of Baiyangdian habitats left great 
manmade traces that resulted in the reduction of water density. We found interesting patterns in the water density image during 2013-2017, shown in Figure 10c, that presents linear textures compared to the naturally smoothing texture in the first phase of 1989-1998 (Figure 10a), although their average values of density across the wetland are similar (Table 2). Those linear objects with the lowest density during 2013-2017 are the manmade non-water features such as cement roads, isolating belts built by dry reeds and soil for fishpond, leisure parks, and paddy fields. The density image during 1988-1998 mostly presents the natural smooth landscape of aquatic vegetation and open water. The density images from these three phases indicate the evolution of landscapes from the natural and delicate pattern of wetland to the fragmented and patchy textures with lots of linear belts. We know that the linear belts would largely damage the ecological and hydrological system of wetland as they block the water cycles, animal migration route and ecological channels of aquatic plants and waterfowl there.

The density in the second phase showed drier features, where the average density and open water extent across the wetland were the minimum, corresponding to the precipitations among the three phases (Table 2 and Figure 4).

\section{Conclusions}

We investigated the sunbelt changes of wetland habitats for the open water and aquatic vegetation in space and time in Baiyangdian from 1984 to 2017 using the multi-temporal Landsat data to address what the natural wetland habitats and landscapes should be from the changing evidences. We found that,

(1) The evidence of open water and aquatic vegetation in the wetland changing from 1984 to 2017 showed phasic changes in three phases: 1988-1998, 1999-2011 and 2013-2017, which are mostly caused by artificial activities. The artificial activities damaged the wetland by decreasing the water flowing into wetland due to massive water consumption in its upstream watersheds. On the other hand, the results demonstrated the artificial water recharge implemented by governmental wetland management has supported the basic demand of water in wetland.

(2) The water body and aquatic vegetation only were remained $61 \%$ of the whole wetland currently while they accounted for $94 \%$ during the early years of 1989-1999. A total of 38\% of wetland range is disturbed by artificial activities such as cultivating rice and lotus, fish farming, built-up, and leisure, currently. It has to be noticed that the northwestern wing of wetland and the areas around the northeastern edge of wetland are at the risk of wetland loss as farmers drain the water of wetlands to grow crops there frequently.

(3) The water environment in wetland habitats showed improved trend from the 2010s owing to the wetland restoration and protection project implemented by the government, which demonstrated the encouraging effects of environment management starting from the year 2010. The current landscape of wetland habitats, however, presents fragmented and patchy textures cut by lots of linear belts that are blocking the water cycles and ecological channels of aquatic plants and animals in the wetland compared to the landscape of wetland habitats in the first phase of 1989-1999. The landscape of wetland habitats during 1989-1999 mostly show us a natural spatial pattern with less human disturbances. This landscape may be what we should restore in the wetland environment reconstruction.

Using the satellite long-term observations, we can not only better understand current landscapes of wetland habitats and their changes, but also identify original or less human disturbed landscapes through tracking their historical changing evidences, which would support environmental restoration and protection management. Additionally, the reviews of historical changes in wetland habitats, which were addressed in this study, are related to the Sustainable Development Goals (SDG) in SDG 15 (Life on land) (url: http://www.fao.org/sustainable-development-goals/goals/goal-15/en/). The long-term changes of open water extent could be one of SDG indicators for assessment of sustainably managed water and provide a basis for evidence-based decision-making. 
Author Contributions: Conceptualization, L.L. (Liping Lei) and Z.Z.; methodology, Z.Z., L.L. (Liping Lei) and Z.H., software, Z.Z., Z.H., and Y.S.; validation, Z.Z. and Z.H.; formal analysis, Z.Z. and L.L. (Liping Lei); investigation, Z.Z., L.L. (Liwei Li), Z.H. and Y.S.; resources, L.L. (Liping Lei), X.W. and X.G.; data curation, X.W.; writing-original draft preparation, Z.Z.; writing-review and editing, L.L. (Liping Lei) and Z.Z.; visualization, Z.Z., L.L. (Liwei Li) and Z.H.; supervision, X.W. and X.G.; project administration, X.W. and L.L. (Liping Lei); funding acquisition, L.L. (Liping Lei) and X.W. All authors have read and agreed to the published version of the manuscript.

Funding: This research was financially supported by the National Key Research and Development Program of China (2016YFB0501505).

Acknowledgments: Special thanks are given to the anonymous reviewers and editors for their constructive comments. In addition, Zhijie Zhang wants to thank, in particular, the patience, care and support from Yuanjie Zhang over the past years.

Conflicts of Interest: The authors declare no conflict of interest.

\section{References}

1. Mitsch, W.J.; Gosselink, J.G.; Anderson, C.J.; Zhang, L. Wetland Ecosystems; John Wiley: New York, NY, USA, 2009.

2. Gallant, A.L. The challenges of remote monitoring of wetlands. Remote Sens. 2015, 7, 10938-10950. [CrossRef]

3. Tiner, R.W.; Lang, M.W.; Klemas, V.V. Book review-Remote sensing of wetlands applications and advances. Photogramm. Eng. Remote Sens. 2016, 82, 917-918.

4. Ji, L.; Zhang, L.; Wylie, B.K. Analysis of dynamic thresholds for the normalized difference water index. Photogramm. Eng. Remote Sens. 2009, 75, 1307-1317. [CrossRef]

5. Ludwig, C.; Walli, A.; Schleicher, C.; Weichselbaum, J.; Riffler, M. A highly automated algorithm for wetland detection using multi-temporal optical satellite data. Remote Sens. Environ. 2019, 224, 333-351. [CrossRef]

6. Feyisa, G.L.; Meilby, H.; Fensholt, R.; Proud, S.R. Automated Water Extraction Index: A new technique for surface water mapping using Landsat imagery. Remote Sens. Environ. 2014, 140, 23-35. [CrossRef]

7. Fisher, A.; Flood, N.; Danaher, T. Comparing Landsat water index methods for automated water classification in eastern Australia. Remote Sens. Environ. 2016, 175, 167-182. [CrossRef]

8. Gong, P.; Niu, Z.G.; Cheng, X.; Zhao, K.Y.; Zhou, D.M.; Guo, J.H.; Liang, L.; Wang, X.F.; Li, D.D.; Huang, H.B.; et al. China's wetland change (1990-2000) determined by remote sensing. China Earth Sci. 2010, 53, 1036-1042. [CrossRef]

9. Schaffer-Smith, D.; Swenson, J.J.; Barbaree, B.; Reiter, M.E. Three decades of Landsat-derived spring surface water dynamics in an agricultural wetland mosaic; Implications for migratory shorebirds. Remote Sens. Environ. 2017, 193, 180-192. [CrossRef] [PubMed]

10. Fickas, K.C.; Cohen, W.B.; Yang, Z. Landsat-based monitoring of annual wetland change in the Willamette Valley of Oregon, USA from 1972 to 2012. Wetl. Ecol. Manag. 2015, 24, 73-92. [CrossRef]

11. Wulder, M.A.; Li, Z.; Campbell, E.M.; Virtanen, J.-P.; Hobart, G.W.; Hermosilla, T.; Coops, N.C. A national assessment of wetland status and trends for Canada's forested ecosystems using 33 years of earth observation satellite data. Remote Sens. 2018, 10, 1623. [CrossRef]

12. Daniel, D.; Craig, D.; Monica, P. Mapping and hydrologic attribution of temporary wetlands using recurrent landsat imagery. Wetlands 2016, 36, 431-443.

13. Niu, Z.; Gong, P.; Cheng, X.; Guo, J.; Wang, L.; Huang, H.; Shen, S.; Wu, Y.; Wang, X.; Wang, X.; et al. Geographical characteristics of China's wetlands derived from remotely sensed data. Sci. China Ser. D Earth Sci. 2009, 52, 723-738. [CrossRef]

14. Niu, Z.; Zhang, H.; Wang, X.; Yao, W.; Zhou, D.; Zhao, K.; Zhao, H.; Li, N.; Huang, H.; Li, C.; et al. Mapping wetland changes in China between 1978 and 2008. Chin. Sci. Bull. 2012, 57, 2813-2823. [CrossRef]

15. Chen, L.; Jin, Z.; Michishita, R.; Cai, J.; Yue, T.; Chen, B.; Xu, B. Dynamic monitoring of wetland cover changes using time-series remote sensing imagery. Ecol. Inform. 2014, 24, 17-26. [CrossRef]

16. Zhu, J.; Zhou, Y.; Wang, S.; Wang, L.T.; Liu, W.L.; Li, H.T.; Mei, J.J. Analysis of changes of Baiyangdian Wetland from 1975 to 2018 based on remote sensing. J. Remote Sens. 2019, 23, 1993-2002.

17. Zhang, M.; Gong, Z.; Zhao, W.; Duo, A. Landscape pattern change and the driving forces in Baiyangdian wetland from 1984 to 2014. Acta Ecol. Sin. 2016, 36, 4780-4791. [CrossRef] 
18. Chen, X.; Wang, F.; Lu, J.; Li, H.; Zhu, J.; Lv, X. Simulation of the effect of artificial water transfer on carbon stock of Phragmites australis in the Baiyangdian Wetland, China. Science 2017, 2017, 1-11. [CrossRef]

19. Li, F.; Xie, Y.; Yang, G.; Ren, B.; Hou, Z.-Y.; Qin, X.-Y. Preliminary survey on aquatic vegetations in Baiyangdian Lake. J. Appl. Ecol. 2008, 19, 1597-1603.

20. Yang, C. Analysis on the deposited quantity variation and its influenced factors in BaiyangDian. Groundwater 2010, 32, 110-112.

21. Li, C.M.; Ye, X.Q.; Wu, M.; Shao, X.X. Effects of water depth and coexistence on growth characteristics of Phragmites australis and Typha domingensis. Wetl. Sci. 2015, 13, 609-615.

22. Yang, W.; Yang, Z.; Qin, Y. An optimization approach for sustainable release of e-flows for lake restoration and preservation: Model development and a case study of Baiyangdian Lake, China. Ecol. Model. 2011, 222, 2448-2455. [CrossRef]

23. Zhou, Y.; Yan, G. Diversion recharge to maintain the ecological effect of Baiyangdian Lake. Water Sci. Eng. Technol. 2012, 6, 29-32.

(C) 2020 by the authors. Licensee MDPI, Basel, Switzerland. This article is an open access article distributed under the terms and conditions of the Creative Commons Attribution (CC BY) license (http://creativecommons.org/licenses/by/4.0/). 